\title{
Modeling of the post-seismic slip of the 2003 Tokachi-oki earthquake $M 8$ off Hokkaido: Constraints from volumetric strain
}

\author{
Tetsuo Takanami ${ }^{1,2}$, Alan T. Linde ${ }^{1}$, Selwyn I. Sacks ${ }^{1}$, Genshiro Kitagawa ${ }^{3,4}$, and Hui Peng ${ }^{3,5}$ \\ ${ }^{1}$ Department of Terrestrial Magnetism, Carnegie Institution of Washington, 5241 Broad Branch Road NW, Washington, DC 20015, U.S.A. \\ ${ }^{2}$ Earthquake Research Institute, the University of Tokyo, 1-1-1 Yayoi, Bunkyo-ku, Tokyo 113-0032, Japan \\ ${ }^{3}$ The Institute of Statistical Mathematics, 10-3 Midori-cho, Tachikawa, Tokyo 190-8562, Japan \\ ${ }^{4}$ Research Organization of Information and Systems, Kamiya-cho Central Place 2F 4-3-13, Toranomon, Minato-ku, Tokyo 105-0001, Japan \\ ${ }^{5}$ School of Information Science and Engineering, Central South University, Changsha, China
}

(Received April 4, 2012; Revised November 28, 2012; Accepted December 13, 2012; Online published August 23, 2013)

\begin{abstract}
A Sacks-Evertson borehole volumetric strainmeter (SE strainmeter) at a site located $105 \mathrm{~km}$ from the epicenter of the mainshock recorded a clear slow strain event following the $2003 M_{\mathrm{w}} 8.0$ Tokachi-oki earthquake (September 25, 2003, 19:50:06 UTC). This consisted of an episode of contraction for 4 days followed by expansion for 23 days. GPS sites in southeastern Hokkaido also recorded displacement changes during the same time interval. We use quasi-static calculations to generate synthetic waveforms for the measured quantities. All the data are satisfied by a propagating line source 2-stage model of slow reverse slip, uniform amplitude of $50 \mathrm{~cm}$, with rupture propagation velocities of constant $9 \mathrm{~cm} / \mathrm{s}$ (first stage) and exponentially decreasing from 3 to $0.7 \mathrm{~cm} / \mathrm{s}$ (second stage). This post-seismic slip event is taken to be coplanar with the main shock rupture on the upper plane of the double Wadati-Benioff seismic zone (DSZ), and largely overlaps the seismic rupture. Regular earthquakes release only about $30 \%$ of the plate motion in this section of the subduction zone; post-seismic slip appears to account for at least some of the deficit.
\end{abstract}

Key words: Post-seismic slip event, volumetric strainmeter, 2003 Tokachi-oki earthquake, aftershock activity, state space approach.

\section{Introduction}

The Hokkaido corner in the southernmost Kuril trench is the site of great earthquakes due to the subduction of the Pacific Plate beneath Hokkaido, Japan, at a rate of 8.3 $\mathrm{cm} / \mathrm{yr}$ (Fig. 1). There are two recent such earthquakes: the 1952 Tokachi-oki earthquake ( $M$ 8.2), and the 2003 Tokachi-oki earthquake $(M 8.0)$. The rupture zone of the 2003 Tokachi-oki earthquake is close to the source region of the 1952 Tokachi-oki earthquake as described by Yamanaka and Kikuchi (2003), suggesting that such large earthquakes occurred repeatedly at fixed asperities. Yamada et al. (2005) located precisely many hypocenters of aftershocks by using a high density OBS array (47 stations) and showed that few of the aftershocks occurred where large slip took place during the main shock. Further, Ito et al. (2004) showed that the most thrust faulting aftershocks of $M 4$ and greater with a nodal plane similar to the main shock concentrated along the plate boundary to the east of the large stress-drop zone of the main shock.

In a study of GPS data of GEONET sites in Hokkaido, for the period between September 4, 2003, and March 6, 2004, the time evolution of its post-seismic slip, together with the coseismic slip distribution were estimated (Ozawa et al., 2004). Miyazaki et al. (2004) estimated the spatial

Copyright (C) The Society of Geomagnetism and Earth, Planetary and Space Sciences (SGEPSS); The Seismological Society of Japan; The Volcanological Society of Japan; The Geodetic Society of Japan; The Japanese Society for Planetary Sciences; TERRAPUB.

doi:10.5047/eps.2012.12.003 and temporal evolution of post-seismic slip in the 30 days following the mainshock. Using GPS data, they showed that there was significant post-seismic slip following the mainshock. Their findings placed most of the slip in an area to the northeast and southwest of the coseismic slip but we note that the results did not fit well the distribution of the vertical displacements. Baba et al. (2006) estimated a Ushaped 1-yr post-seismic slip distribution encircling the coseismic slip, using GPS and ocean bottom pressure data. Miyazaki and Larson (2008) used 30-second GPS data to derive a model of post-seismic slip during the $\sim 1$ hour before the largest aftershock, and also for the first 4 hours after the mainshock. They concluded that there was significant post-seismic slip in the region between the slip maxima of the mainshock and that of the largest aftershock, as well as downdip of those zones. Fukuda et al. (2009), using 5 hours of GPS data immediately following the mainshock, also found slow post-seismic slip roughly in the area between the main, and the largest, aftershock.

Here, we re-examine this post-seismic slip episode by utilizing dilatational strain data from a Sacks-Evertson borehole strainmeter (Sacks et al., 1971) at the Urakawa Seismological Observatory of Hokkaido University (KMU) in southern Hokkaido, Japan (Fig. 1) with the objective of determining what additional constrains can be placed on the parameters of the post-seismic slip. Clearly, with only one strainmeter site we cannot claim a complete solution but we will see if our model based on strain changes can also satisfy the displacement data from those GPS sites in south- 


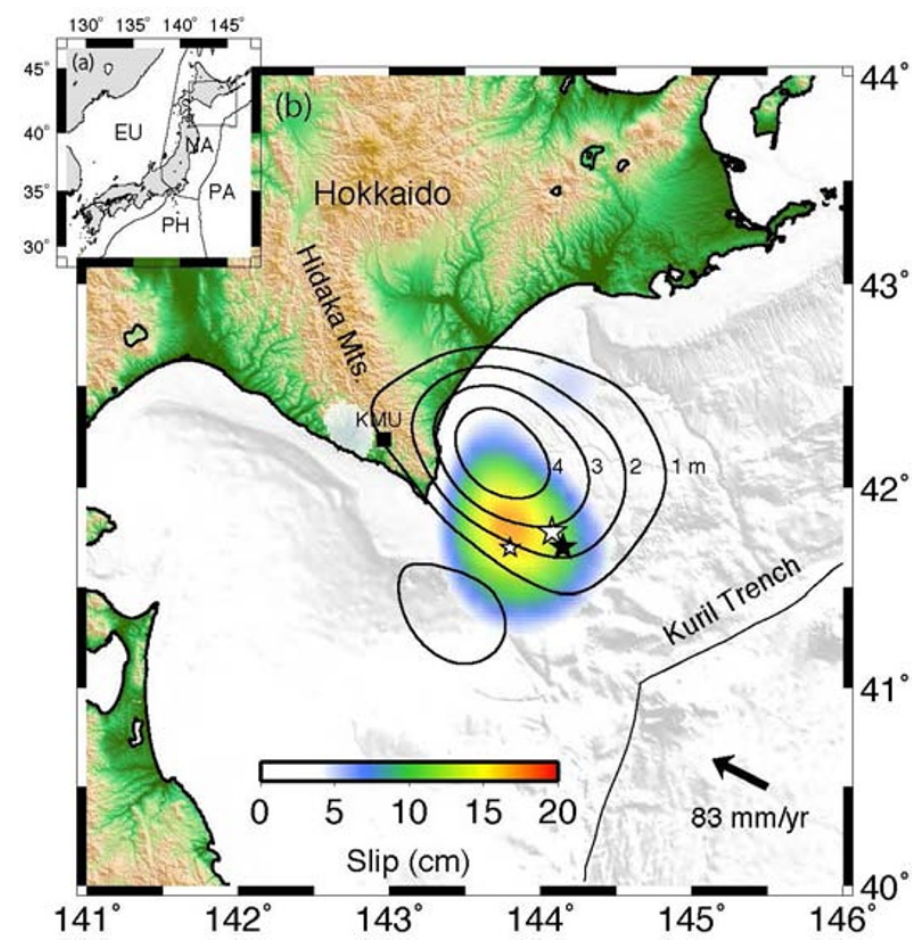

Fig. 1. (a) Tectonic setting of Japanese island. Solid lines indicate plate boundaries. EU, PH, PA, and NA denote Eurasian, Philippine Sea, Pacific and North American plates, respectively. (b) Magnified map of the rectangular area in Fig. 1(a). The solid square denotes the borehole station of the Sacks-Evertson strainmeter. The solid star denotes the epicenter of the 1952 Tokachi-oki earthquake. Open big and small stars denote the epicenters of the 2003 Tokachi-oki earthquake and its largest aftershock, respectively. Color scale shows the cumulative afterslip for 5 hours following the main shock (Fukuda et al., 2009). Contours with a 1-m interval represent the coseismic slip distribution of the main shock estimated by Miyazaki and Larson (2008). The thick arrow shows the relative motion of the Pacific plate with respect to the North American plate computed based on the work of DeMets et al. (1994).

east Hokkaido in the general vicinity of the strainmeter site.

Strain changes in near-surface crustal rock have contributions from barometric pressure changes, from Earth tides, and precipitation, in addition to any tectonic changes of importance to this study. Additionally, the continuity of the data stream is occasionally interrupted due to equipment failure or loss of power. To remove extraneous influences, we first apply a state-space model that was developed for detecting coseismic changes of groundwater levels (Kitagawa and Matsumoto, 1996; Matsumoto et al., 2003) to the strain data recorded at KMU. The resulting signal decomposition provides a corrected strain signal, showing a clear strain event consisting of contraction for about 4 days, and then expansion for about 23 days, following the 2003 Tokachi-oki earthquake. We assume, as did previous investigators, that the source for this strain event is coplanar with the mainshock and additionally that the slip is in the same direction as the coseismic slip and is uniform over our entire model surface.

\section{Observation and Data Processing}

Our primary data are 6 months of strain change observations, starting about 4 months before the 2003 Tokachioki earthquake, recorded by a SE strainmeter in a 110-mdeep borehole at KMU (Takanami, et al., 1998). The site is about $105 \mathrm{~km}$ from the earthquake epicenter (Fig. 1). The strainmeter has a sensitivity of about $10^{-11}$, large dynamic range and constant response to strain from zero frequency to $20 \mathrm{~Hz}$ (Sacks et al., 1971). The strain data are now logged on site and also sent by telemetry to the Institute of Seismology and Volcanology, Hokkaido University, Sapporo, Hokkaido, but, in 2003, we had only telemetered data. We also use GPS data from a number of sites in southeast Hokkaido to confirm the validity of our model and to provide constraints on the along strike length of the slow rupture source.

Figure 2 shows the time series of one-hour sampled strain data for the period from June 01, 2003, to November 30, 2003. There are 2 gaps in the data due to loss of power and these also resulted in a reset of the strainmeter, as evidenced by an offset in the record. The second of these power failures was due to shaking from the studied earthquake and, unfortunately, resulted in the loss of 12 hours of data. We removed these offsets by incorporating a step function time series. Our preprocessing technique allows both the estimation of missing data and the removal of artificial offsets (Kitagawa, 2010), but our analyses do not use any of the results of these aspects of the data processing. Of course, any tectonic strain changes during the interval cannot be restored. Thus, we have no strain data from which to estimate coseismic offsets due to the mainshock and the largest aftershock; nor can we see changes due to any post-seismic slip during that interval.

In general, the raw strain data includes the response due to barometric pressure changes, Earth tides, and precipitation. In order to decompose stably such responses, we used a state-space model with regression covariance; this was originally developed to decompose groundwater level 
(a)

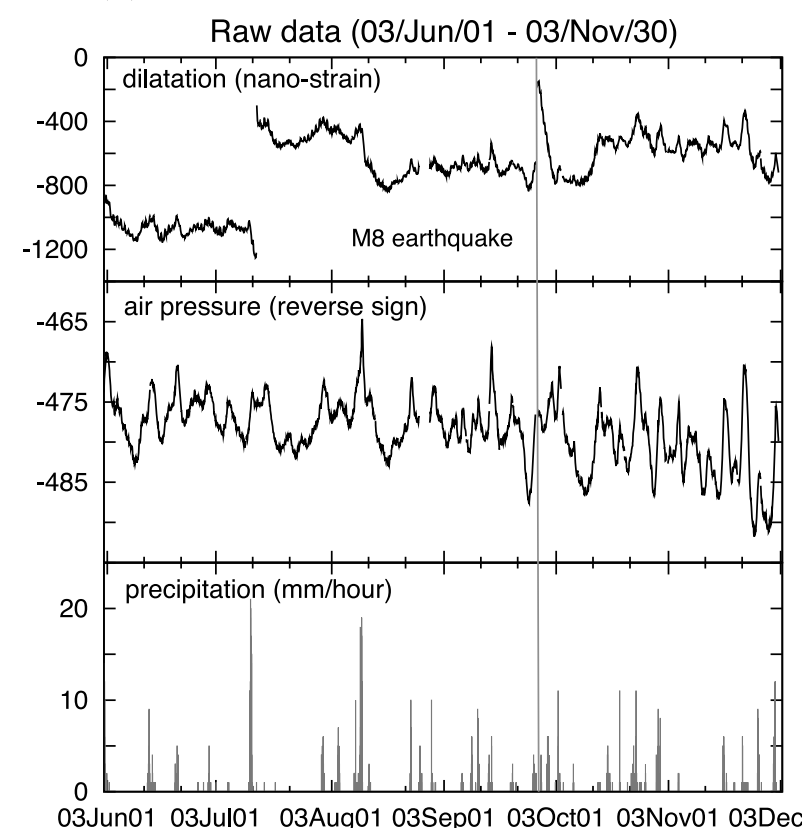

(b)

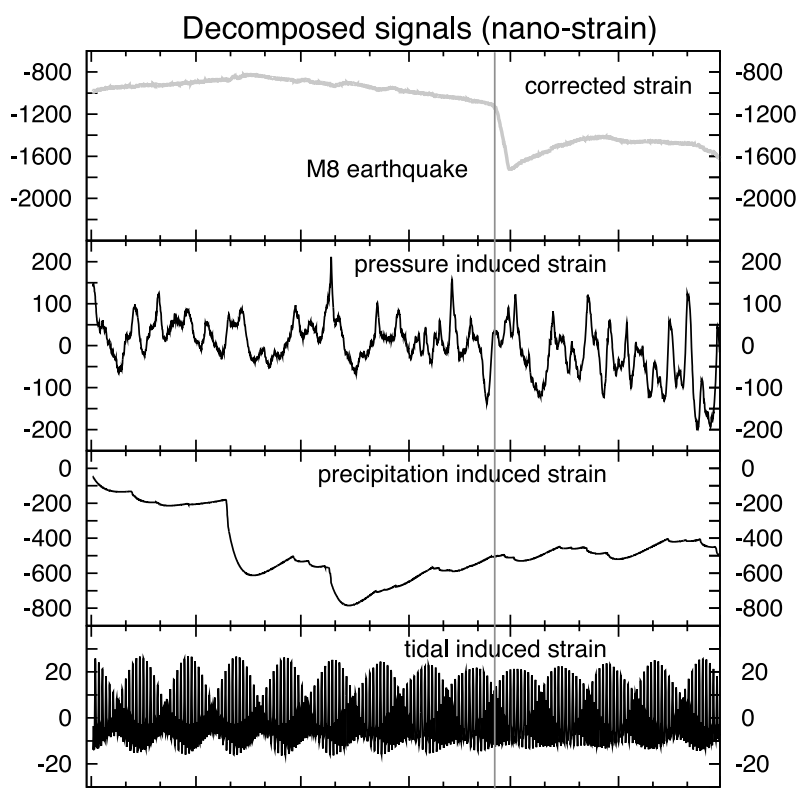

Fig. 2. (a) Observation data. Top, middle, and bottom indicate raw strain, air pressure (in units of digitizer counts), and precipitation. (b) Decomposed signals. From top to bottom, observation through pre-processing for jump and missing data and trend component, pressure induced strain, precipitation induced strain, and tidal induced strain for 4 major constituents. The vertical line marks the time of the mainshock. Note, in particular, the non-linear transfer function for effects due to precipitation. Time is based in JST.

into the effects of barometric pressure, Earth tide, and precipitation (Kitagawa and Matsumoto, 1996; Matsumoto et al., 2003). Here, we use it to analyze the borehole strain time series,

$$
\begin{aligned}
& \text { corrected } \operatorname{Strain}_{n}={ }_{\mathrm{obs}} \operatorname{Strain}_{n}-\left(P_{n}+E_{n}+S_{n}+\varepsilon_{n}\right), \\
& \varepsilon_{n} \sim N\left(0, \sigma^{2}\right), \quad n=1, \ldots, N .
\end{aligned}
$$

where $N$ is the number of observations. $P_{n}, E_{n}, R_{n}, S_{n}$ and $\varepsilon_{n}$ are air pressure effect, Earth tide effect, precipitation effect, jump effect and observation noise components, respectively. The corrected strain is expressed by using the following first-order trend model (Kitagawa and Gersch, 1984).

$$
\begin{aligned}
& \text { corrected } \operatorname{Strain}_{n}=\text { corrected } \operatorname{Strain}_{n-1}+w_{n}, \\
& w_{n} \sim N\left(0, \tau^{2}\right), \quad n=1, \ldots, N .
\end{aligned}
$$

The other components are as given below,

$$
\begin{aligned}
P_{n} & =\sum_{i=0}^{m} a_{i} p_{n-1}, \\
E_{n} & =\sum_{i=0}^{l} b_{i} e t_{n-i}, \\
R_{n} & =\sum_{i=1}^{k} c_{i} R_{n-i}+\sum_{i=1}^{k} d_{i} r_{n-i}, \\
S_{n} & =\sum_{i=1}^{n_{s}} \eta_{i} s_{i, n},
\end{aligned}
$$

where $p_{n}, e t_{n}$, and $r_{n}$ are the observed air pressure, theoretical Earth tide and observed precipitation, respectively.
$S_{n}$ expresses the jump of the level due to instrument maintenance or breakdown, where $\eta_{i}$ is an unknown jump amplitude and $s_{i, n}$ is the step function defined by $s_{i, n}=0$ for $i \leq n_{i}$ and $s_{i, n}=1$ for $i>n_{i} . n_{i}$ is the jump occurrence time of the $i$-th jump and is assumed to be known. For the precipitation effect, we used the ARMAX type model (Box and Jenkins, 1976) as given by the model (5) because a precipitation effect may continue for a very long time following the precipitation. The regression coefficients $a_{i}$ and $b_{i}$ can be estimated by the Kalman filter. On the other hand, $c_{i}$ and $d_{i}$ need to be estimated by numerically maximizing the likelihood function. Once the parameters of these models are estimated by the maximum likelihood method, we can interpolate the missing values of strain data by using Kalman filtering and a fixed-interval smoother. After applying such a state-space approach to the strain data to separate these responses, the resulting signal is our best estimate of the change in tectonic strain (upper panel, Fig. 2(b)). The orders of the models $m, l$, and $k$ are selected by searching for the optimum state-space model having the smallest AIC (Akaike, 1973) value, which is obtained by maximizing the likelihood of the model and optimizing the model parameters. $n_{s}$ is the number of jumps in the observation data.

This time series shows a clearly anomalous strain change for at least 27 days following the earthquake. The data do not preclude continuing slip over a longer time interval as has been shown by Ozawa et al. (2004) but since we cannot readily recognize such strain changes we limit our analysis to the clearly observable strain event. We now seek to determine the source of this signal. 
(a)

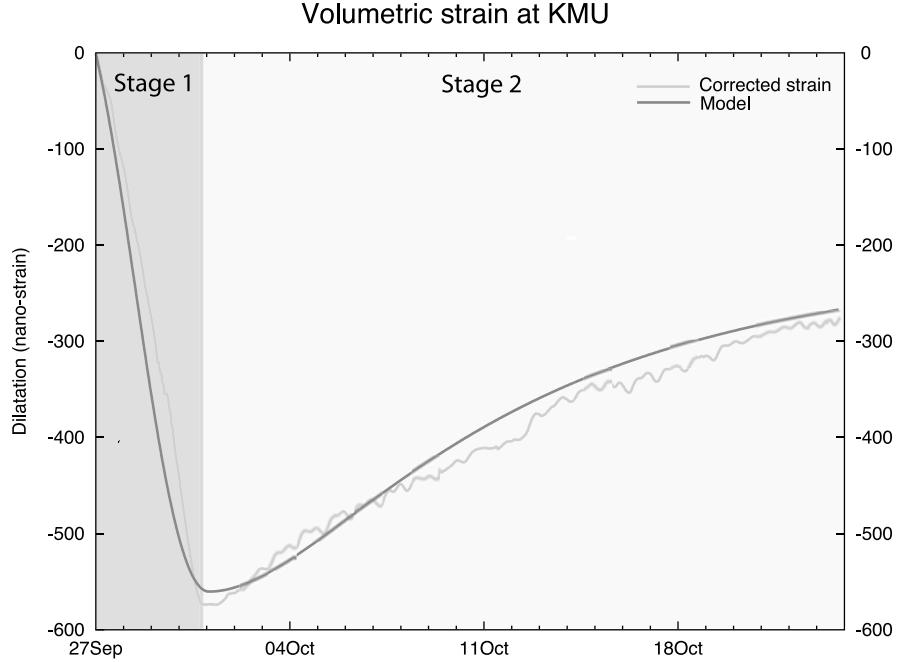

(b)

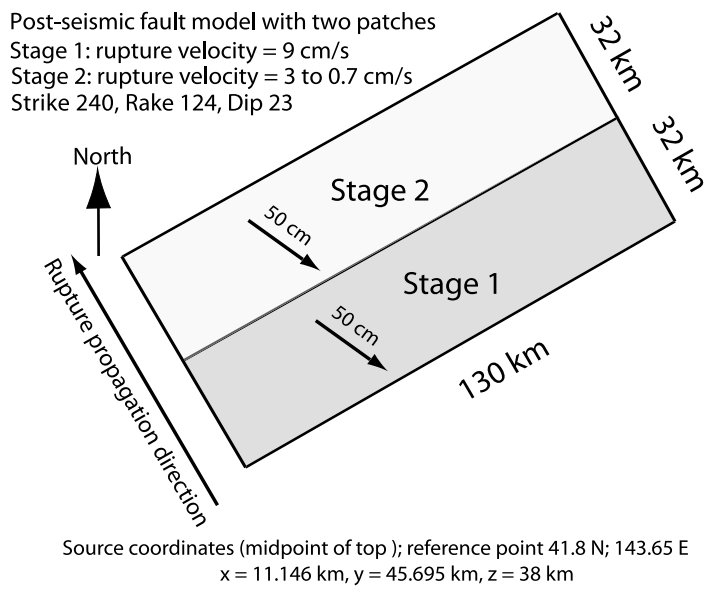

Fig. 3. (a) Observed data (light grey line) and model curve (dark grey line) calculated for the propagating fault model. (b) Schematic propagating fault model for slow slip event consisting of Stage 1 (dark grey) and 2 (light grey). We have a line source, with uniform slip over the whole surface, propagates slowly down-dip.

\section{Propagating Fault Model for Post-Seismic Slip}

Previous studies of post-seismic strain changes in locations of GPS sites (Ozawa et al., 2004; Miyazaki and Larson, 2008; Fukuda et al., 2009) solved for source models coplanar with the mainshock rupture. We also take that approach and additionally assume the same direction for the slip vector as for the mainshock (Geographical Survey Institute, 2004). This approach is supported by the work of Ito et al. (2004), who pointed out that the mechanisms of the aftershocks, distributed along the boundary between the Pacific and the North American plates, are similar to that of the main event, indicating a thrust fault with a nodal plane dipping to the northwest. The location of such aftershocks corresponds to the upper zone of the double-planed WadatiBenioff seismic zone (DSZ) imaged along the southernmost Kuril trench using relocated hypocenters by Katsumata et al. (2003). We use the mainshock fault plane solution from the Geographical Survey Institute (2004).

By focusing on the strain data, we bring additional constraints on models for the post-seismic slip. Our approach is to look for the simplest model that will satisfy the strain record and then check by comparing calculated displacements with GPS observations in southeast Hokkaido from GEONET (GPS Earth Observation Network System) of the Geospatial Information Authority of Japan (GSI) and the temporary GPS survey by Takahashi et al. (2004). That the strain record is characterized by a change in sign during the course of the event is indicative of a propagating source. In contrast to horizontal displacements, vertical displacements and dilatation experience sign changes that are diagnostic of source depth. When we apply the very reasonable constraint that the source of the post-seismic slip is coplanar with the mainshock rupture (strike $240^{\circ}$, dip $23^{\circ}$ ) and the slip vector has the same rake angle $\left(124^{\circ}\right)$ as for the mainshock, as given by GSI (2004), we immediately find that the strain record supplies strong constraints on the extent of the source in the dip direction and also requires that the rupture propagates down-dip. To minimize the number of free pa- rameters, we also assume that the slip amplitude is constant over the slow rupture surface and that the rupture front is a horizontal line source.

We use expressions for deformation given by Okada (1992) due to shear failure on a rectangular surface in a uniform elastic half-space. We generate a quasi-static time series by successively calculating the deformations as the rupture surface grows due to a line source (extending over the length of the fault in the strike direction) propagating down-dip with velocities determined as indicated below. This technique has been used previously, e.g. in Linde et al. (1996) and Liu et al. (2009). The upper edge of the slow rupture surface (to the south-east) cannot be shallower than in the model; slow rupture with a slip direction as in the mainshock on the shallower extension of that plane will produce expansion (positive) strain at KMU rather than the initial observed contraction. The lower limit of Stage 1 (see Fig. 3(b) and caption for the characterization of the two stages, with the first corresponding to compressive strain at KMU, and the second to expansion) is fixed since, at that position, the strain produced at KMU changes from contraction to expansion, corresponding to the reversal in the data as shown in Fig. 3(a). The amplitude of the strain change in Stage 1 requires $50 \mathrm{~cm}$ of slip and we fit the duration and shape of the strain change extremely well by using a constant rupture velocity of $9 \mathrm{~cm} / \mathrm{s}$ (Fig. 3(a)). We cannot similarly unambiguously constrain the lower limit of rupture for Stage 2. But we minimize the number of free parameters by taking a constant slip amplitude over the whole slip surface, so then the observed strain change amplitude for Stage 2 determines the lower limit of slip. This coincidentally results in the down-dip rupture width being the same for both stages. For this stage, a constant rupture velocity does not produce a comparably good fit to the shape of the data; the model curve would initially increase too slowly. To improve the fit to the shape of the curve, we used an exponentiallyslowing rupture velocity that slows from $3 \mathrm{~cm} / \mathrm{s}$ to $0.7 \mathrm{~cm} / \mathrm{s}$. Note that this added complexity does not affect the calcu- 

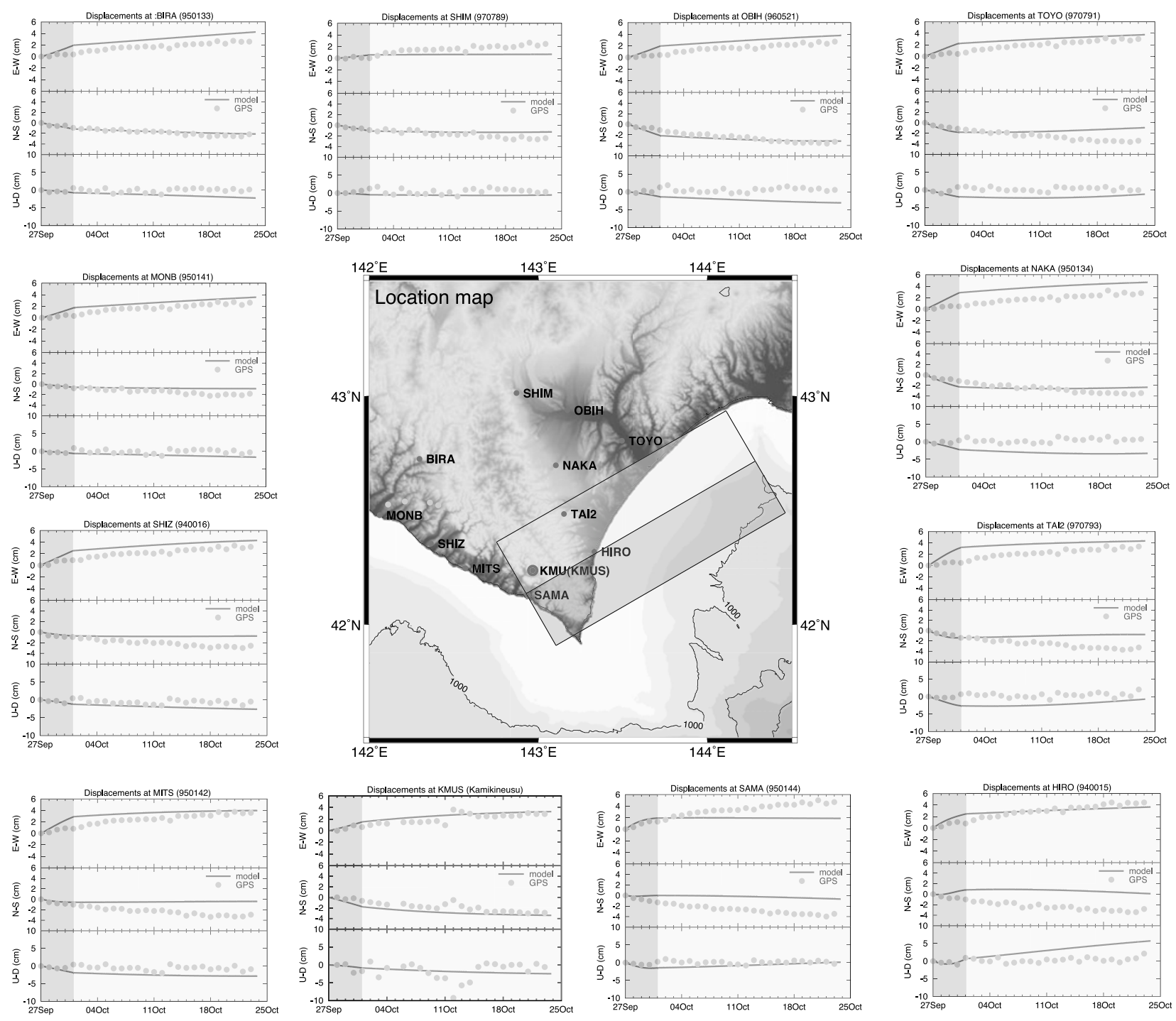

Fig. 4. Comparison of displacements calculated for the fault model (dark line) with those estimated from data at 12 selected GPS stations. Locations of SE strainmeter station of KMU, GPS stations of GEONET (small circles) and temporary GPS station (big circle) are indicated in the central location map together with fault planes for two stages (dark grey then light grey) of slow slip. Comparison is carried out from 27 September to 25 October (UTC). GPS data was used only to constrain the length along strike of the slip model; down-dip dimensions and slip amplitude were determined using only KMU strain data. Nevertheless the agreement between the GPS data and model calculations is very good.

lated amplitude for Stage 2.

The schematic geometry of faults in Stages 1 and 2 is illustrated in Fig. 3(b). The fault parameters (fault areas, fault slips, rupture velocities, and depths) are $130 \times 32 \mathrm{~km}^{2}$, $50 \mathrm{~cm}, 9 \mathrm{~cm} / \mathrm{s}$ and $38 \mathrm{~km}$ for Stage 1 , and $130 \times 32 \mathrm{~km}^{2}$, $50 \mathrm{~cm}$, and 3 to $0.7 \mathrm{~cm} / \mathrm{s}$ (exponentially decreasing) and $50.5 \mathrm{~km}$ for Stage 2, respectively. The total seismic moment released slowly is $1.4 \times 10^{20} \mathrm{~N} \mathrm{~m}$ (equivalent to $M_{\mathrm{w}}=7.4$ ).

\section{Comparison of Model with GPS Data}

It is impossible to determine the fault length using only data from a single strainmeter site, but GPS data assist in that respect (Fig. 4). Requiring a reasonable fit to the GPS data allows good control of the southwest extent of the slow rupture. The northeast extent is less well controlled by the data in Fig. 4; rather, we limit the northeast extent to fit well with the extent of coseismic rupturing. This limit, for our very simple source model, is rather similar to that in Ozawa et al. (2004) and in Miyazaki et al. (2004); those studies use data from many more GPS sites. In Fig. 4, we show the data from 12 GPS sites in southeast Hokkaido together with the calculated displacements for the model derived as described above. The fit of model curves to the data is surprisingly good considering that we determined the down-dip extent of rupturing and the slip amplitude solely from the strain data and that we imposed uniform slip over a rupture surface that is a simple rectangular shape.

For GPS sites whose data plots are not shown, three close to Cape Erimo record significantly larger EW displacements than those calculated from our model, while some sites to the north have larger (negative) NS displacements. The discrepancy could be reduced by allowing some clockwise rotation of the slip vector as a function of strike direction from southwest to northeast. But, even without adding any complexity to our extremely simple model, the overall fit to all sites is very good given that we did not use these data to control the slip solution; clearly, our model captures the essentials of the post-seismic rupture. We do not fit well 
the horizontal displacements at GPS sites to the NE of our model; this is not surprising since our model is primarily based on the strain record from KMU to the southeast end of the model surface. That aspect could be improved by including additional slip in the vicinity of those GPS sites (e.g. see Ozawa et al., 2004) without any noticeable change in the calculated strain at KMU.

There have been several studies of this post-seismic slip event based on analyses of GPS data, e.g. Miura et al. (2004), Miyazaki et al. (2004), Ozawa et al. (2004), Murakami et al. (2006), and Uchida et al. (2009). The latter two present an analysis over a longer period than in our study. Compared with our very simple model, all of these studies solve for models with many more parameters. These solutions characteristically show large slip amplitudes shallow in the subduction zone (depth $<20 \mathrm{~km}$ ) at rather larger distances from the land-based observation points. The models also have slip concentration on the subduction interface under Hokkaido. We note that the shallow slip in those models is not compatible with the strain record (as noted above, slip in that area will result in a positive strain change at KMU). Also, that shallow slip causes negative vertical displacements at GPS sites close to the coast where the data show uplift; this has to be offset by adding slip patches under the land. Baba et al. (2006) show that the land-based GPS data provide poor resolution for slip in the shallow parts of the subduction zone. Previously-published models are in conflict with the observed strain change data whereas our very simple model, derived primarily to fit the strain data, also fits the GPS data very well for those sites in the vicinity of our model.

\section{Relationship between Post-Seismic Slip and Af- tershock Activity}

In Fig. 5, we show aftershock activity during the first 10 days of the post-seismic slip event. We note that there is a significant change in the earthquake rate at about the time of completion of the Stage 1 rupture (Fig. 5(a)). In Figs. 5(b) and 5(c) we show the locations of those aftershocks for the entire duration of Stage 1, and the first 6 days of Stage 2. The majority of the aftershocks cluster to the east of the combined post-seismic slip zones, suggesting that the afterslip behavior changes at a longitude of about $144.2^{\circ} \mathrm{E}$. The strain rate (at KMU), and the average rate of aftershock occurrence, are $154 \times 10^{-9}$ strain/day and 13.6 events/day during Stage 1 , and $13 \times 10^{-9}$ strain/day and 5.4 events/day in the earlier part of Stage 2, respectively (Fig. 5(a)). We speculate that the higher rate of seismicity during Stage 1 could be because post-seismic slip up till that time is closer to the zone of aftershocks and thus has a greater impact on the shear stress on the more easterly part of the subduction zone, leading to an increase in the seismicity rate.

We also note (Figs. 5(b) and 5(c)) that the post-seismic slip area is complementary to that with the large majority of aftershocks, as pointed out by Ito et al. (2004). Mochizuki et al. (2005) interpreted strong reflections at the plate boundary within the aseismic regions as implying aseismic slip between the plates. Aftershocks occur mainly to the east of about $144.2^{\circ} \mathrm{E}$ and south of $42.5^{\circ} \mathrm{N}$, whereas continuing post-seismic slip dominates the post-seismic re- lease to the west. Earlier GPS-based studies found postseismic slip to the north of the $42.5^{\circ} \mathrm{N}$ limit. (As discussed above, we discount any post-seismic slip shallower in the subduction zone, i.e. to the east of $144.2^{\circ} \mathrm{E}$ and south $42.5^{\circ} \mathrm{E}$, as proposed in earlier GPS-based studies, because such slip violates the strain observations, and a subsequent study by Baba et al. (2006) shows that the GPS data has very low resolving power for such slip.) This dividing line is not simply along a depth contour of the subduction, and so the differing characteristics are not simply a function of depth. It may be suggestive of differing fault zone rheologies. Machida et al. (2009) showed that the high $V_{p} / V_{s}$ anomaly is positioned above the largest slip area of the 2003 Tokachi-oki earthquake, estimated by Yamanaka and Kikuchi (2003), and suggested that it may relate to fluid flow during the main shock.

\section{Conclusion}

We applied state-space modeling techniques to enable the removal of offsets, barometric pressure change effects, solid Earth tides, and precipitation effects, from the strain recorded by an SE strainmeter at KMU, southeast Hokkaido. Particularly noteworthy is the successful removal of the strains induced in a non-linear fashion by precipitation. The remaining trend is a significantly improved estimate of geodetic strain and clearly shows continuing post-seismic strain following the $M 8$ Tokachi-oki earthquake.

By assuming, for this post-seismic slip, a source coplanar with the seismic rupture plane, we are able to place strong constraints on the down-dip extent and amplitude of the post-seismic slip by using only the dilatational strain data. We limit the northeast extent of our model to match the coseismic rupture and then find that we match the GPS data surprisingly well with the other slip parameters determined solely from the strain data at a single station. We minimize the number of free parameters in the model by having the simplest possible geometry and slip parameters. We have two rectangular slip surfaces, one for each stage of the strain event that consists of contraction followed by expansion. These two sources have equal lengths and widths, and we impose a uniform slip vector over the complete source.

Miyazaki and Larson (2008) concentrated on GPS displacement changes during the first 4 hours after the mainshock, an interval during which we have no strain data due to power failure at the observation site. Their model has a slip patch contiguously up-dip from our model; if that slip propagated downward it would merge into our slip area. Ozawa et al. (2004) and Miyazaki et al. (2004) studied a longer time interval but, for the duration of our study, they proposed a large patch of post-seismic slip up-dip from the seismic rupture at a depth less than $20 \mathrm{~km}$, in addition to slip at depths more comparable to those of our model. Such models are not compatible with the strain record; they produce a large expansion (positive) signal. Also, as we noted above, the GPS network has a rather low resolving capability for slip in those distance shallow area (Baba et al., 2006). Both studies use data from a large number of GPS stations and invoke quite a complex source model. The GPS data in those two studies show low amplitude changes con- 


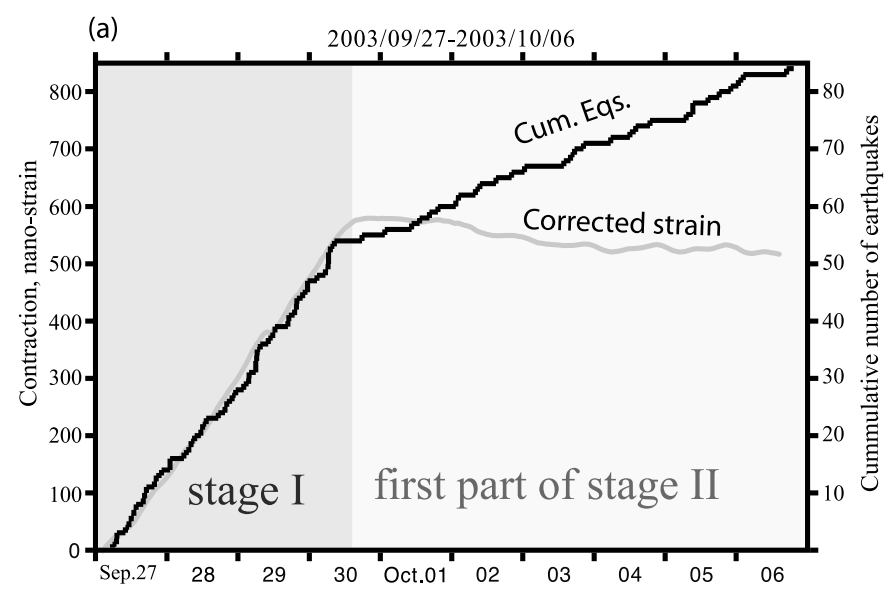

(b) 2003/09/27 00:00-2003/10/06 24:00 N=85

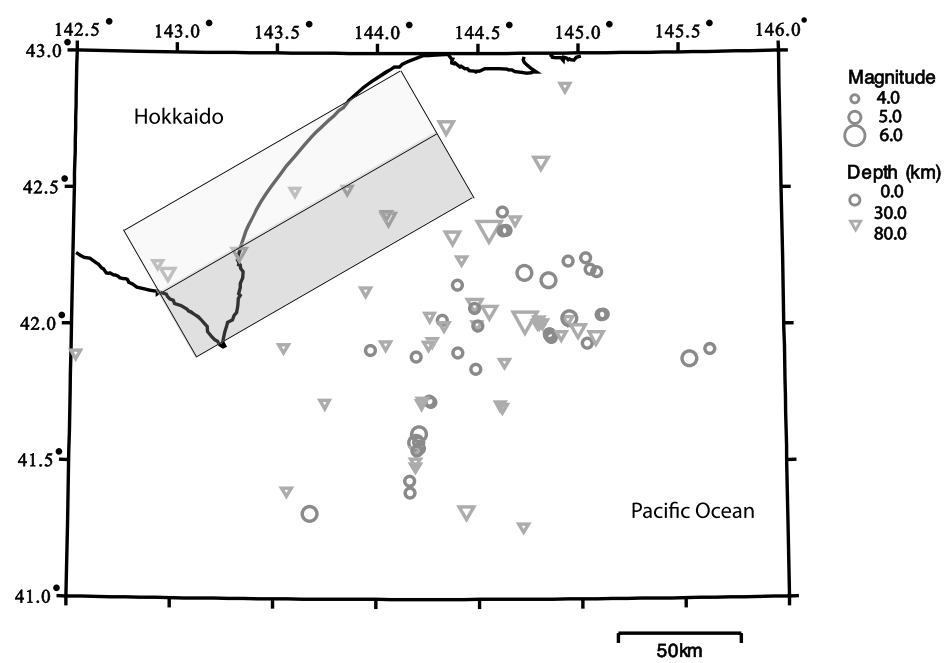

(c) 2003/09/27 00:00-2003/10/06 24:00 N=936

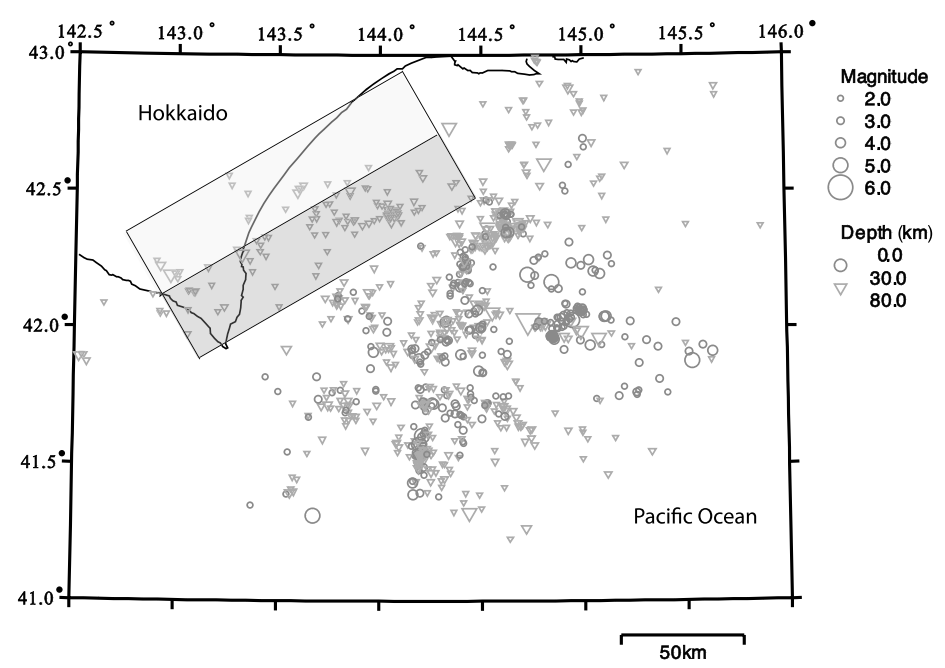

Fig. 5. (a) Comparison of strain rate with occurrence rate of aftershocks of $M 4$ and over located in and around the aftershock area $\left(41^{\circ} \mathrm{N} \sim 43^{\circ} \mathrm{N}\right.$, $142.5^{\circ} \mathrm{E} \sim 146^{\circ} \mathrm{E}$ ) from September 27 to October 06 (JST). Light and black lines indicate variations of strain (contraction positive) and cumulative number of aftershocks. Maps of aftershocks during 10 days following the mainshock; (b) aftershocks $m=4$ or more; (c) aftershocks $m=2$ or more. These aftershocks are all at the depths of the subducting interface. Note that very few earthquakes $m=4$ or more occur in the area where we have slow slip to satisfy the strain transient; rather, they are in the adjacent areas. 
tinuing after the end of our Stage 2. Strain amplitudes for such small long-period changes would be below our detection threshold.

Additionally, we note an intriguing relation: the areas experiencing aftershocks and post-seismic slip are complementary, but are not separated by depth. We have no simple explanation for this but the observation appears to be robust.

Acknowledgments. The authors thank M. Acierno, B. Schleigh, and B. Pandit from DTM of Carnegie Institution of Washington, and T. Ogawa, M. Takada and Y. Tanioka from ISV of Hokkaido University for their valuable support. Reviews and corrections by two anonymous reviewers are greatly appreciated. GMT (Wessel and Smith, 1991) was used to produce the figures. We used the unified Japan Meteorology Agency (JMA) earthquake catalog with Hokkaido University, Hirosaki University, Tohoku University, Tokyo University, Nagoya University, Kyoto University, Kochi University, Kyushu University, Kagoshima University, Shizuoka Prefecture, Yokohama City, Tokyo Metropolis, JMA, Natural Research Institute for Earth Science and Disaster Prevention, National Institute of Advanced Industrial Science and Technology (AIST), Japan Agency for Marine-Earth Science and Technology (JAMSTEC), and Hot Springs Research Institute of Kanagawa Prefecture. Mapping for epicenters were carried out by using the Seismicity Analysis System TSEIS (http://wwweic.eri.utokyo.ac.jp/analysis.html).

\section{References}

Akaike, H., Information theory and an extension of the maximum likelihood principle, in Proceeding of 2nd International Symposium on Information Theory, edited by B. N. Petrov and F. Csaki, 267-281, Akademiai-Kiado, Budapest, Hungary, 1973.

Baba, T., K. Hirata, T. Hori, and H. Sakaguchi, Offshore geodetic data conducive to the estimation of the afterslip distribution following the 2003 Tokachi-oki earthquake, Earth Planet. Sci. Lett., 241, 281-292, doi:10.1016/k.epsl.2005.10.019, 2006.

Box, G. E. P. and G. M. Jenkins, Time Series Analysis: Forecasting and Control, 2th ed., 575 pp., San Francisco, Holden-Day, 1976.

DeMets, C., R. G. Gordon, D. F. Argus, and S. Stein, Effect of recent revisions to the geomagnetic reversal timescale on estimates of current plate motions, Geophys. Res. Lett., 21(20), 2191-2194, 1994.

Fukuda, J., K. M. Johnson, K. M. Larson, and S. Miyazaki, Fault friction parameters inferred from the early stages of afterslip following the 2003 Tokachi-oki earth- quake, J. Geophys. Res., 114, B04412, doi:10.1029/2008JB006166, 2009.

Geographical Survey Institute, Crustal movement in Hokkaido district, in Report of the Coordinating Committee for Earthquake Prediction, 71, edited by Geographical Survey Institute, pp. 135-187, Tsukuba, Japan, 2004.

Ito, Y., H. Matsubayashi, H. Kimura, T. Matsumoto, Y. Asano, and S. Sekiguchi, Spatial distribution for moment tensor solutions of the 2003 Tokachi-oki earthquake $\left(M_{\mathrm{JMA}}=8.0\right)$ and aftershocks, Earth Planets Space, 56, 301-306, 2004.

Katsumata, K., N. Wada, and M. Kasahara, Newly imaged shape of the deep seismic zone within the subducting Pacific plate beneath the Hokkaido corner, Japan-Kuril arc-arc junction, J. Geophys. Res., 108(B12), 2565, doi:10.1029/2002JB002175, 2003.

Kitagawa, G., Introduction of Time Series Modeling, 289 pp., Chapman \& Hall, New York, 2010.

Kitagawa, G. and W. A. Gersch, A smoother prior-state-space modeling of time series with trend and seasonality, J. Ame. Statist. Assoc., 79, 378389, 1984.

Kitagawa, G. and N. Matsumoto, Detection of coseismic changes of underground water level, J. Ame. Statist. Assoc., 91, 521-528, 1996.

Linde, A. T., M. T. Gladwin, M. J. S. Johnston, R. L. Gwyther, and R. G. Bilham, A slow earthquake sequence on the San Andreas Fault, Nature, 383, 65-68, 1996.

Liu, C., A. T. Linde, and I. S. Sacks, Slow earthquakes triggered by typhoons, Nature, 459, 833-836, doi:10.1038/nature08042, 2009.
Machida, Y., M. Shinohara, T. Takanami, Y. Murai, T. Yamada, N. Hirata, K. Suyehiro, T. Kanazawa, Y. Kaneda, H. Mikada, S. Sakai, T. Watanabe, K. Uehira, N. Takahashi, M. Nishino, K. Mochizuki, T. Sato, E. Araki, R. Hino, K. Uhira, H. Shiobara, and H. Shimizu, Heterogeneous structure around the rupture area of the 2003 Tokachi-oki earthquake $(M w=8.0)$, Japan, as revealed by aftershock observations using Ocean Bottom Seismometers, Tectonophysics, 465, 164-176, 2009.

Matsumoto, N., E. A. Roeloffs, and G. Kitagawa, Hydrological response to earthquakes in the Haibara well, central Japan-I. Groundwater level changes revealed using state space decomposition of atmospheric pressure, rainfall and tidal responses, Geophys. J. Int., 155, 885-898, 2003.

Miura, S., Y. Suwa, A. Hasegawa, and T. Nishimura, The 2003 M8.0 Tokachi-Oki earthquake-How much has the great event paid back slip debts?, Geophys. Res. Lett., 31, L05613, doi:10.1029/2003GL019021, 2004.

Miyazaki, S. and K. M. Larson, Coseismic and early postseismic slip for the 2003 Tokachi-oki earthquake sequence inferred from GPS data, Geophys. Res. Lett., 35, L4302, doi:10.1029/2007GL032309, 2008.

Miyazaki, S., P. Segall, J. Fukuda, and T. Kato, Space time distribution of afterslip following the 2003 Tokachi-oki earthquake: Implications for variations in fault zone frictional properties, Geophys. Res. Lett., 31, L06623, doi:10.1029/2003GL019410, 2004.

Mochizuki, K., M. Nakamura, J. Kasahara, R. Hino, M. Nishino, A Kuwano, Y. Nakamura, T. Yamada, M. Shinohara, T. Sato, and P. P. Moghaddam, Intense PP reflection beneath the aseismic forearc slope of the Japan Trench subduction zone and its implication of aseismic slip subduction, J. Geophys. Res., 110, B01302, doi:10.1029/2003JB002829, 2005.

Murakami, M., H. Suito, S. Ozawa, and M. Kaidzu, Earthquake triggering by migrating slow slip initiated by M8 earthquake along Kuril Trench, Japan, Geophys. Res. Lett., 33, L09306, doi:10.1029/2006GL025967, 2006.

Okada, Y., Internal deformation due to shear and tensile faults in a halfspace, Bull. Seismol. Soc. Am., 82, 1018-1040, 1992.

Ozawa, S., M. Kaizu, M. Murakami, T. Imakiire, and Y. Hatanaka, Coseismic and postseismic crustal deformation after the Mw 8 Tokachi-oki earthquake in Japan, Earth Planets Space, 56, 675-680, 2004.

Sacks, I. S., S. Suyehiro, D. W. Evertson, and Y. Yamagishi, SacksEvertson strainmeter, its installation in Japan and some preliminary results concerning strain steps, Pap. Meteorol. Geophys., 22, 195-208, 1971.

Takahashi, H., S. Nakao, N. Okazaki, J. Koyama, T. Sagiya, T. Ito, F. Ohya, K. Sato, Y. Fujita, M. Hashimoto, Y. Hoso, T. Kato, T. Iinuma, J. Fukuda, T. Matsushima, Y. Kohno, and M. Kasahara, GPS observation of the first month of postseismic crustal deformation associated with the 2003 Tokachi-oki earthquake $\left(M_{\mathrm{JMA}} 8.0\right)$, off southeastern Hokkaido, Japan, Earth Planets Space, 56, 377-382, 2004.

Takanami, T., T. Ogawa, S. I. Sacks, A. T. Linde, and I. Nakanishi, Long-period volume-strain seismogram of the 8 August 1993 Esashioki earthquake, off southwest of Hokkaido, Japan and its source mechanism, J. Fac. Sci. Hokkaido Univ., Ser. VII (Geophysics), 11(2), $523-$ 543, 1998.

Uchida, N., S. Yui, S. Miura, T. Matsuzawa, A. Hasegawa, Y. Motoya, and M. Kasahara, Quasi-static slip on the plate boundary associated with the 2003 M8.0 Tokachi-oki and 2004 M7.1 off-Kushiro earthquakes, Japan, Gondwana Res., 16, 527-533, 2009.

Wessel, P. and W. H. Smith, Free software helps map and display data, Eos Trans. AGU, 72, 441-446, 1991.

Yamada, T., M. Shinohara, T. Kanazawa, N. Hirata, Y. Kaneda, T. Takanami, H. Mikada, K. Suyehiro, S. Sakai, T. Watanabe, K. Uehira, Y. Murai, N. Nishino, K. Mochizuki, T. Sato, E. Araki, R. Hino, K. Uhira, H. Shiobara, and H. Shimizu, Aftershock distribution of the 2003 Tokachi-oki earthquake derived from high-dense network of ocean bottom seismographs, J. Seismol. Soc. Jpn., 57, 281-290, 2005.

Yamanaka, Y. and M. Kikuchi, Source processes of the recurrent Tokachioki earthquake on September 26, 2003, inferred from teleseismic body waves, Earth Planets Space, 55, e21-e24, 2003.

T. Takanami (e-mail: takanami69@gmail.com), A. T. Linde, S. I. Sacks, G. Kitagawa, and H. Peng 